\title{
IMPLEMENTACIJA WMS U POSLOVANJU SKLADIŠNE FUNKCIJE PREDUZEĆA „GEPARD”
}

\section{IMPLEMENTATION OF WMS IN THE BUSINESS OF STORAGE SPACE IN „GEPARD“ COMPANY}

\author{
Marijana Batak, Fakultet tehničkih nauka, Novi Sad
}

\section{Oblast - LOGISTIKA}

Kratak sadržaj - Predmet rada jesu osnovni pojmovi logistike, sa naglaskom na značaj skladišnih procesa u logistici. Primenom inženjerskih metoda, identifikovani su glavni uzroci koji utiču na proces skladištenja u preduzeću „,Gepard“. Na osnovu rezultata, predloženo je unapređenje skladišnog poslovanja u preduzeću, kupovinom WMS sistema.

Ključne reči: Logistika, Skladište, Unapređenje, WMS,

Abstract - In this paper, basic concepts of logistics are presented, with an emphasis on importance of warehouse processes in logistics. By applying engineering methods the main causes that affect warehouse processes at the „Gepard" company, were identified. Based on the resolution, it was suggested to improve the enterprise warehouse business by purchasing WMS system.

Keywords: Logistics, Warehouse, Improvement, WMS

\section{UVOD}

Zadatak menadžmenta skladištenja jeste da dizajnira i optimizuje sisteme za sve vrste skladišta, komisionarenja, od ulaska do izlaska, preko svih reprodukcija. Sistem optimizacije obuhvata i softverske i hardverske logističke instrumente.

Skladište je logistički prostor, gde je roba stacionirana odnosno na raspolaganju, s obzirom da ne učestvuje $u$ procesu proizvodnje ili pružanju usluga. Tek kasnije roba se uključuje u proces proizvodnje novih vrsta roba ili pružanju usluga.

Problem koji se nameće poslednjih godina jeste kako unaprediti poslovanje određenih organizacija. Tržište postaje sve više konkurentno, što je dobro za korisnike istih, ali menadžmentu to predstavlja problem.

Nove tehnologije su temelj za nove proizvode i one stvaraju mogućnost za bolju vezu sa kupcima. Uloga informacionih tehnologija je $\mathrm{u}$ menjanju poslovnih odnosa, ali i poboljšanju aktivnosti unutar nekog preduzeća.

Zato su informacioni sistemi u svim sferama modernog poslovanja pronašli primenu i u logistici.

\section{NAPOMENA:}

Ovaj rad proistekao je iz master rada čiji mentor je bio dr Stevan Milisavljević, van. prof.

\section{LOGISTIKA}

Za poreklo reči logistika, u naučnoj i stručnoj literaturi, vezuju se različiti stavovi i pristupi, koji su u osnovi ispravni, s obzirom da sam pojam logistike može da ima više značenja. Poreklo reči logistika, dolazi iz grčkog jezika i reči "logos" koja označava: pojam, razum, odnos ili razlog.

Nauka logos predstavlja ispravno rasuđivanje, mišljenje i zaključivanje. Po nekima, to bi značila veština proračunavanja, pa su se samim tim u Staroj Grčkoj nazivali službenici, čiji je zadatak bio da proračunaju državne potrebe [1].

\section{ZALIHE}

U proizvodnom preduzeću, zalihe su sirovine koje se skladište radi proizvodnje. $U$ maloprodaji, zalihe su proizvodi za prodaju koji se drže u skladištima ili su izloženi na policama. Zalihe u lancu snabdevanja postoje zbog razlika u nabavci sirovina, poluproizvoda, gotovih proizvoda i tražnje za njima.

Upravljanje zalihama se u osnovi svodi na cost benefit analizu, tj. na analizu troškova i koristi od držanja zaliha. Zapravo, utvrđivanje optimalne količine zaliha zahteva balansiranje između troškova držanja zaliha i korisnosti koja se ostvaruje raspolaganjem tim zalihama [2].

\section{SKLADIŠTENJE \\ 4.1. Pojam skladišta}

Gotovi proizvodi koji su neophodni drugim poslovnim sisemima u različitim vremenskim intervalima zahtevaju zalihe. Zalihe postoje kako bi se savladale prostorne i vremenske neusklađenosti potrošnje i razmene. Kako bi mogle da se sačuvaju do vremena kada je neophodno da se otpreme, mora im se obezbediti određeni uslovi čuvanja zaliha.

Prostor namenjen za čuvanje, dopremu i otpremu zaliha naziva se skladište. Čuvanjem, smeštanjem i optremanjem robe iz skladišta bavi se skladišna služba.

Kako neki materijali na tržištu nisu mogli da se nabave, zbog čega je to uticalo na proizvodnju i isporuku proizvoda, dovelo je pojave skladišta. Kada bi postojala savršena organizacije proizvodnje, koja nabavlja neophodne materijale sa snabdevenog tržišta, potreba za skladišnim prostorom ne bi postojala.

Struktura pogona određuje način upravljanja skladištima i distribucionim centrima. 
Mnoga preduzeća zanemaruju skladištenje i ne umeju da ga prepoznaju kao izvor za smanjenje troškova i poboljšanja produktivnosti integralne logistike [3].

Skladište može da izravna neujednačenost između ponude i potražnje. Kada ponuda premašuje potražnju, skladište čuva proizvode do zahteva kupca.

\subsection{Funkcije skladišta}

Osnovne funkcije skladišta uključuju premeštanje, čuvanje i prenos informacija. Za pravilno skladištenje proizvoda, premeštanje je nužno, a to se odvija u četiri odvojena područja:

1. Primanje dolazeće robe od prevoznika i obavljanje provere kvaliteta i kvaniteta,

2. Prijem robe iz prijemnih platformi i njihovo premeštanje do određenog mesta za čuvanje unutar skladišta,

3. Odabir naručenih proizvoda (komisionarenje) za ispunjenje narudžbi kupaca, što uključuje proveru, pakovanje i transport do otpremnih rampi,

4. Otrpema robe prema van do kupaca određenim načinom prevoza.

Čuvanje se odnosi na fizičko raspolaganje proizvodom unutar skladišta. Čuvanje može biti privremeno ili polutrajno. Privremeno bi značilo čuvanje proizvoda koji su nužni za dopunu zaliha. Polutrajno čuvanje se odnosi na zalihe koje premašuju trenutne potrebe i nazivaju se sigurnosne zalihe.

Prenos informacija se javlja u isto vreme dok se proizvod premešta i skladišti. Menadžment uzima informacije o obimu zaliha, lokaciji zaliha, protoku, iskorišćenosti prostora i ostale informacije nužne da bi se osiguralo uspešno funkcionisanje skladišta.

Informacije se mogu koristiti za procenu učinkovitosti skladištenja ispitivanjem stope iskorišćenosti opreme, produktivnosti rada i iskorišćenosti prostora.

\section{PODACI O PREDUZEĆU}

Preduzeće „Gepard“ D.O.O iz Novog Sada osnovano je oktobra 1992. godine kao privatno preduzeće, a od marta 1998. godine posluje kao jednočlano društvo sa ograničenom odgovornošću, i po svom obliku organizovanosti je privatno preduzeće radi obavljanja proizvodne delatnosti, proizvodnje obuće, sa sedištem u Novom Sadu, u ul. Koči Ivana br.2.

Postojeći poslovni objekat u svemu zadovoljava kriterijume za obavljanje delatnosti proizvodnje obuće, slika 1.

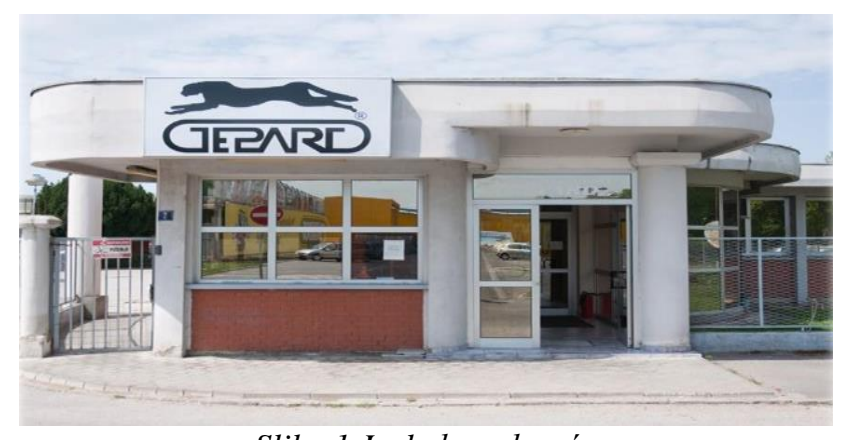

Slika 1-Izgled preduzeća

Od osnivanja do danas, preduzeće proizvodi namensku obuću za poznate domaće kupce, kao što su Vojska
Srbije, Ministarstvo unutrašnjih poslova, NIS ad, Elektroprivreda Srbije, Srbija šume, kao i mnoge druge privredne i sportske organizacije i sl.

Danas preduzeće u sve većem obimu obavlja proizvodnju i za inostrane kupce ili izradom gotove obuće ili putem doradnih poslova. Broj radno angažovanih lica se uvećavao iz godine u godinu, od 3 zaposlena na samom početku, do 100 zaposlenih danas.

Iz svega prethodno navednog, može se zaključiti da se preduzeće konstantno širi. Preduzeće „Gepard“ se bavi proizvodnjom isključivo hardverskih proizvoda. Iako je teško održati vodeće pozicije, po ostvarenim rezultatima poslovanja i konstantno opravdavati zvanična priznanja koja je preduzeće steklo tokom svog rada, Gepard se nalazi u grupi najuspešnijih u grani delatnosti i celokupnoj privredi Republike Srbije. Preduzeće ima za cilj, ne samo očuvanje postojećeg statusa, već proširenje svog delovanja na domaćem $\mathrm{i}$ ino tržištu.

Ono po čemu se „Gepard“ ističe i na čega se ponosi jeste izrada obuće GOODYEAR tehnologijom koju čini oko 180 različitih operacija. Nepotrebno je reći da samo najveći umetnici znaju kako da ih naprave. „Gepard“" dnevno proizvede oko 300 pari GOODYEAR cipela. Osnovna karakteristika GOODYEAR tehnologije jeste dvostruko šivenje. Ono što ove cipele nude je izvanredna snaga i zadržavanje oblika, a đon se može menjati iznova i iznova. U cilju pokrivanja većeg dela tržišta Gepard se orijentisao i na maloprodaju, te danas postoji pet maloprodajnih objekta sa tendencijom da isti postoje u svim većim gradovima. $\mathrm{Za}$ sada su to dve poslovne jedinice u Novom Sadu, po jedna u Nišu, Sremskoj Mitrovici i Kikindi. Gepard obuća je namenjena široj populaciji i nudi dobar odnos cena i kvalitet [4].

\section{SNIMAK STANJA \\ 6.1. Skladišni prostor}

Skladišno prostor firme „Gepard“ nalazi se na u sklopu firme u ulici Koče Ivana 2, u Novom Sadu. Skladišni prostor omogućuje skladištenje širokog asortimana gotove robe. $\mathrm{Na}$ osnovu projektovanog kapaciteta dnevna količina robe u prijemu iznosi 100 komada na dan, a kapacitet skladišta je oko 3.000 paletnih mesta. Osnovna jedinica za smeštaj artikala je standardna drvena euro paleta 1200 × $800 \times 144 \mathrm{~mm}$. Objekat ima dimenzije 100 x 33,4 m. Visina objekta je 8,2 m. U pitanju je visokoregalno skladište. Objekat je izrađen od betonske konstrukcije, zidovi su izolovani panelima, a krov je termički i hidro izolovan. Skladišni prostor pokriva površinu od $2000 \mathrm{~m}^{2}$.

Svako paletno mesto i svaka paleta sa robom obeleženi su jedinstvenim barkod oznakama. Radnici u skladištu su opremljeni modernim uređajima, bar kod skenerima i mobilnim računarima sa bežičnom komunikacijom.

Skladišni prostor je prekriven signalom bežične mreže pomoću koje su ručni računari u vezi sa magacinskim softverom. Svaki deo skladišta pokriven je signalom bežične mreže, kako se ne bi desilo da računari ostanu bez signala. Bežična komunikacija obezbeđena je sistemom koji se sastoji od 14 access pointova koji su raspoređeni duž skladišta sa obe strane.

U svaku prostoriju doveden je optički link od centralnog sviča, po jedan sa obe strane skladišta. Na kraju svakog 
optičkog segmenta nalazi se 8-portni svič (osim u poslednjoj prostoriji gde postoji samo po jedan accespoint po strani) na koji su vezana po tri acces-pointa.

Acces pointovi su podešeni da rade na istom kanalu kako bi korisnici mogli da vrše roaming kada prelaze iz dometa jednog uređaja u domet drugog uređaja, a da pri tome ne gube vezu sa serverom.

\subsection{Proces skladištenja}

Skladištenje robe obuhvata sledeće procese:

Prijem robe počinje dobijanjem "naloga za prijem" na kojem se vide svi podaci koji definišu robu. Magacioner preuzima nalog za prijem i vrši raspodelu robe po paletnim mestima. Sistem prepoznaje da li se u skladištu već nalazi slična roba i na osnovu parametara koji mu se definišu i podataka o robi daje predlog paletnih mesta na koje treba odložiti robu. Na magacioneru ostaje izbor da li će prihvatiti ponudu ili će sam izvršiti odabir paletnih mesta [5].

Nakon odabira lokacija na koje treba smestiti robu štampa se lista skladištenja na kojoj se vide svi podaci o robi, kao i brojevi paletnih mesta na koja se roba treba odložiti. Izborom opcije "štampa nalepnica" na termalnom štampaču vrši se štampa nalepnica sa bar-kodom na kojima se nalaze podaci o robi i paletnom mestu gde treba da bude odložena. Radnik (viljuškarista) upotrebom ručnog računara sa skenerom, vrši skeniranje bar-koda na listi za skladištenje, nakon čega se na displeju ručnog računara pojavljuju sve stavke koje on mora da odradi. Nakon toga vrši se kvalitativna i kvantitativna kontrola robe, lepljenje etiketa sa bar-kodom na svaku paletu pojedinačno. Ukoliko su izvršene potrebne aktivnosti, paleta se odlaže na definisana paletna mesta. Koristeći ručni računar, viljuškarista vrši skeniranje bar-kodova sa nalepnica na paletama i na paletnim mestima. Softverom je predviđena zabrana odlaganja paleta na pogrešna paletna mesta, što je jedan od najvažnijih uslova skladištenja.

Izdavanje robe se vrši na osnovu ,naloga za izdavanje“ koje magacioner dobija kroz instalirani softver. Nakon što prihvati navedeni nalog magacioneru se automatski pojavljuju na monitoru računara svi podaci o robi koju treba isporučiti. Softver sam određuje lokacije sa kojih je potrebno uzeti određenu robu, kao i njihov redosled $\mathrm{u}$ zavisnosti od više kriterijuma koji su zadati. Magacioneru dalje ostaje samo da oštampa „listu za izdavanje“ koju dalje preuzima viljuškarista.

Slično kao i kod prijema robe, viljuškarista, treba da ide od lokacije do lokacije redom kojim su palete sa robom poređane na displeju ručnog računara i izvrši izuzimanje navedene robe iz regala. Kada dođe na odgovarajuću lokaciju viljuškarista skenira bar-kod lokacije da potvrdi da je na dobroj lokaciji (čuje se karakterističan zvuk koji potvrđuje ili opominje ako je na pogrešnoj lokaciji), zatim skenira bar-kod na paleti sa robom (takođe zvučna potvrda ili opomena) i vrši izdvajanje robe (konfekcioniranje) iz regala.

Nakon toga prelazi na sledeću lokaciju i na kraju kad završi konfekcioniranje celokupne količine robe po listi za izdvajanje, izborom opcije „pošalji na server“, potvrđuje da je navedene aktivnosti izvršio. Kada je dobio potvrdu o izvršenim aktivnostima magacioner odabirom softverske opcije „knjiženje“ ažurira podatke u informacionom sistemu, čime se automatski štampa otpremnica kupcu. Uz otpremnicu može se odštampati deklaracija koja prati robu. Slično kao i kod skladištenja, softver ne dozvoljava uzimanje palete čiji se bar kod ne poklapa sa predviđenim bar kodom. Takođe nemoguće je da viljuškarista izdvoji paletu sa robom sa pogrešne lokacije odnosno paletnog mesta.

\section{PREDLOG MERE UNAPREĐENJA}

\subsection{WMS Warehouse Management System}

Kako bi se što kvalitetnije rešili navedeni problem, tendencija većine firmi iz područja pružanja usluga skladištenja robe za račun drugih vlasnika robe implementiraju se informatički sistemi za praćenje i upravljenje skladišnim poslovanjem. Većinom se ti sistemi nazivaju WMS sistemima (Werehouse Management System). To su sistemi koji, osim što sadrže deo programskog rešenja $u$ interakciji su i sa pripadajućom namenskom informatiçkom opremom za rad u skladištu i mrežnom infrastrukturom i opremom. Sistem za upravljanje skladištem (WMS) je ključni deo lanca nabavke, prvenstveno namenjen kontroli kretanja i skladištenja materijala unutar skladišta i beleženje pripadajućih transakcija, uključujući isporuku, prijem, odlaganje i izuzimanje. Ovaj informatički sistem se najbolje može opisati kao sprega napredne tehnologije i procesa rukovanja u cilju optimizacije svih skladišnih funkcija.

Prednosti WMS-a su sledeće:

Brži obrt zaliha: Efikasnom organizacijom rukovanja robom sistem smanjuje vreme cekanja na isporuku, povećava se ažurnost informacija i podržava JIT tehnologija. Posledica je smanjena potreba za dodatnim zalihama što direktno povećava koeficijent obrta zaliha i koeficijent iskorišćenosti kapitala.

Efikasno korišćenje skladišnog prostora: smanjenjem zaliha, a time i potrebnog prostora za zalihe, povećava se skladišni prostor dostupan za skladištenje. Time se postiže znatno efikasnije skladištenje uz optimalno iskorišćenje raspoloživog prostora, efikasno ,pronalaženje" robe za pakovanje i otpremu. Povećanje efikasnosti povećava produktivnost $\mathrm{i}$ smanjuje troškove održavanja opreme $\mathrm{u}$ skladištu [6].

Smanjenje „papirologije": implementacija "real-time" WMS sistema znaĉajno redukuje rad sa papirima koji prate skladišne operacije. Istovremeno, omogućava pravovremene $i$ tačne informacije o kretanju robe. Izveštaji, otpremnice, "packing" liste i drugi dokumenti, koji se obiĉno ĉuvaju kao "hard" kopije, sada se ĉuaju u elektronskoj formi i po potrebi štampaju.

\section{IZBOR WMS REŠENJA}

\subsection{BEL WMS}

BelWMS je najsavremenije rešenje za vođenje i kontrolu skladišnog prostora, koje je prilagodljivo svim tipovima magacina, bez obzira na kapacitet skladišta, broj zaposlene radne snage, količine obrta robe ili tipova materijala.

BelWMS je informatički sistem upravljanja skladištem (WMS) u potpunosti razvijen od strane Logisofta.

Sistem je prilagodljiv i kroji se u skladu sa zahtevima i načinu poslovanja korisnika i u skladu sa modernim 
logističkim principima i pravilima. U stanju je da radi povezan sa ERP i TMS sistemima, ali $\mathrm{i}$ da radi samostalno u slučaju da je to potrebno.

Karakteristike Bel WMS-a su sledeće:

- Upravljanje matičnim podacima (artikli, klijenti, dobavljači, vozači, vozila, itd.),

- Kontrola dokumenata za ulaz i izlaz robe i njihova štampa (prijemnica i otpremnica),

- Formiranje, manipulacija i kontrola transporta (osnova TMS-a),

- Administracija strukture skladišta - blokiranje i oslobađanje paletnih mesta, zoniranje skladišta,

- Kartica artikala - retroaktivni pregled ulaza i izlaza nekog artikla u određenom vremenskom periodu,

- $\quad$ Lager lista - pregled i administrativno rukovođenje robe u skladištu,

- Štampanje novih ili postojećih bar-kod nalepnica za operativni rad u magacinu,

- Administracija korisnika i korisničkih prava pristupa,

SYSTEM ARCHUTECTURE

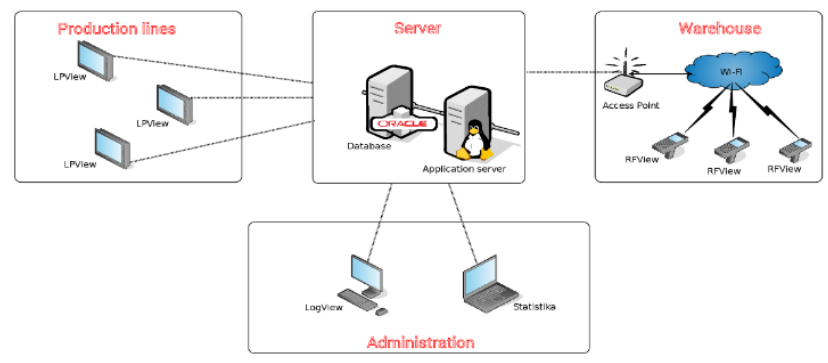

Slika 2-Arhitektura BEL WMS-a

\subsection{IPLUS WMS}

iPlus WMS je paket programskih proizvoda koji dramatično povećavaju efikasnost logističkih procesa. Sistem za vođenje skladišta (magacinsko poslovanje) obezbeđuje korisniku savladavanje velikih količina robe, optimalno korišćenje prostora, vremena, opreme i ljudi. Sistem se, takođe, koristi i za označavanje u proizvodnji po GSI logističkim standardima, uspostavljajući tako potpunu sledljivost robe.

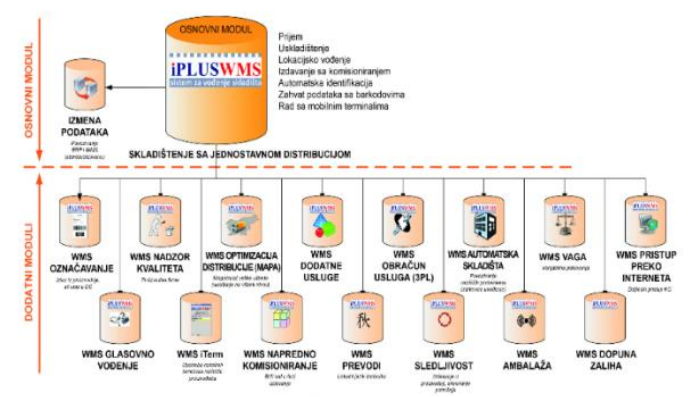

Slika 3-Arhitektura IPLUS WMS-a

\subsection{Izabrano rešenje}

$\mathrm{Na}$ osnovu izvršenog poređenja dva WMS softvera, odlučeno je da Bel WMS softver kompanije LOGISOFT predstavalja bolje rešenje, iz razloga što podržava slične procese kao i softver kompanije LOGOSOFT, iPlus WMS, dok je duplo jeftiniji i svakako se može prilagođavati prema potrebama korisnika, omogućava veći stepen automatizacije, što je od velikog značaja za ovo preduzeće. S obzirom da poslovanje preduzeća "Gepard" odgovara srednjem tipu WMS, usluge Bel WMS softver će im odgovarati.

\section{ZAKLJUČAK}

Upotreba savremenih tehnoloških rešenja odlikuju moderna skladišta, a ona definišu procese preuzimanja, upravljanja i skladištenja robe. U razijenim zemljama, potpuno automatizovana skladišta sve više postaju zastupljena, jer nude niz prednosti.

Dinamičan i harmoničan spoj savremenog logističkog centra, kakav je magacin preduzeća "Gepard" i WMS sistema velikih mogućnosti, Bel WMS-a, maksimalno konfigurabilni i prilagodljiv u svakom smislu, s obzirom da je u potpunosti razvijen od strane Logisoft kompanije, daje sigurnost svakom korisniku logističkih usluga i garanciju da će njegova roba biti skladištena, čuvana $\mathrm{i}$ distribuirana po najvišim standardima.

\section{LITERATURA}

[1] http://plutonlogistics.com/povuci-rucnu/kako-jenastala-rec-logistika/ pristup sajtu 04.10.2018.godine [2] Omerhodžić S., "Finansijski menadžment”Harfo-Graf, Tuzla, 2007.godina

[3] David J.Bloomberg, Stehpen LeMay, Joe B.Hanna, Logistics (2002)

[4] http://www.gepard-obuca.rs/ pristup sajtu

04.10.2018.godine

[5] Interna dokumentacija Instituta za ratarstvo i povrtarstvo, Novi Sad, 2009.

[6] http://logistikaitransport.com/intralogistika/preduslovza-dobro-funkcionisanje-

skladista/?fbclid=IwAR2L00P5V6-

XHAjykcWEMPntJfBB7SOeHeUBaCpq17c2Wxp0TdGt$\underline{\mathrm{X} 15 \mathrm{Fz} 8}$ pristup sajtu 25.05.2020.godine

\section{Kratka biografija:}

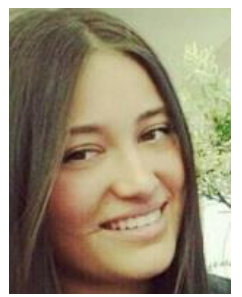

Marijana Batak rođena je u Novom Sadu 1994. god. Master rad na Fakultetu tehničkih nauka iz oblasti Logistike odbranila je 2020.godine.

Kontakt: marijanabatak7@gmail.com 